\title{
Developing our Planetary Plan with an 18th United Nations Sustainable Development Goal: Space Environment
}

\begin{tabular}{|c|c|}
\hline \multicolumn{2}{|c|}{$\begin{array}{l}\text { Author: } \\
\text { Andreas Losch }{ }^{1} \text { (D) }\end{array}$} \\
\hline \multicolumn{2}{|c|}{$\begin{array}{l}\text { Affiliation: } \\
{ }^{1} \text { Department of Systematic } \\
\text { Theology, Faculty of } \\
\text { Theology, University of Bern, } \\
\text { Bern; Department of } \\
\text { Historical and Systematic } \\
\text { Theology, Faculty of Theology } \\
\text { and Religion, University } \\
\text { of Pretoria, Pretoria, } \\
\text { South Africa }\end{array}$} \\
\hline $\begin{array}{l}\text { Research Proje } \\
\text { Project Leade } \\
\text { Project Numb }\end{array}$ & $\begin{array}{l}\text { ct Registration: } \\
\text { : J. Buitendag } \\
\text { er: } 02402343\end{array}$ \\
\hline \multicolumn{2}{|c|}{$\begin{array}{l}\text { Description: } \\
\text { This research is part of the } \\
\text { project, 'Theology and } \\
\text { Nature', directed by } \\
\text { Prof. Dr Johan Buitendag, } \\
\text { Department of Systematic } \\
\text { and Historical Theology, } \\
\text { Faculty of Theology and } \\
\text { Religion, University of Pretoria. }\end{array}$} \\
\hline \multicolumn{2}{|c|}{$\begin{array}{l}\text { Corresponding author: } \\
\text { Andreas Losch, } \\
\text { andreas.losch@theol.unibe.ch }\end{array}$} \\
\hline \multicolumn{2}{|c|}{$\begin{array}{l}\text { Dates: } \\
\text { Received: } 31 \text { Jan. } 2020 \\
\text { Accepted: } 05 \text { June } 2020 \\
\text { Published: } 09 \text { Sept. } 2020\end{array}$} \\
\hline \multicolumn{2}{|c|}{$\begin{array}{l}\text { How to cite this article: } \\
\text { Losch, A., 2020, 'Developing } \\
\text { our Planetary Plan with an 18th } \\
\text { United Nations Sustainable } \\
\text { Development Goal: Space } \\
\text { Environment', HTS Teologiese } \\
\text { Studies/Theological Studies } \\
76(1) \text {, a5951. https://doi.org/ } \\
\text { 10.4102/hts.v76i1.5951 }\end{array}$} \\
\hline $\begin{array}{l}\text { Copyright: } \\
\text { (C) 2020. The A } \\
\text { Licensee: AOS } \\
\text { is licensed unc } \\
\text { Creative Comr } \\
\text { Attribution Lic }\end{array}$ & $\begin{array}{l}\text { uthors. } \\
\text { S. This work } \\
\text { er the } \\
\text { nons } \\
\text { ense. }\end{array}$ \\
\hline \multicolumn{2}{|l|}{ Read online: } \\
\hline 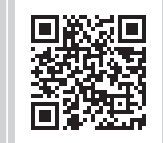 & $\begin{array}{l}\text { Scan this QR } \\
\text { code with your } \\
\text { smart phone or } \\
\text { mobile device } \\
\text { to read online. }\end{array}$ \\
\hline
\end{tabular}

'Planetary sustainability', as developed in this article, is a transitory term, marking the conceptional change from perceiving the Earth as a globe to recognising it rather as a planet. Although the traditional Brundtland sustainability definition comprises ecological, economic and social dimensions to perpetuate the fulfilment of humankind's needs for the next generations, the planetary aspect of sustainability leads to the acknowledgement that there will be an end to human civilisation if humankind does not move into space sooner or later. Concerning space mining, this move might happen in our age. Given this fact, and the contemporary situation concerning space debris, 'ethics of planetary sustainability' as well as space environment ethics are needed. It would also make sense to add an 18th Sustainable Development Goal called 'Space Environment' to the current 17 Global Goals, as a sort of a political demand to complete what then could better be called the 'Planetary Plan'.

Contribution: The increasing economic use of outer space makes it necessary to include this domain in the sustainability discussion. The article calls for an 18th United Nations Sustainable Development Goal "Space Environment", providing theological and philosophical reasoning for the need of an ethics of planetary sustainability.

Keywords: Sustainability; Planetary; Space; Earth; Environment; Heavens; Ecology.

\section{Introduction}

This article is an argument for a truly planetary concept of sustainability, including the idea to add the Earth's 'space environment' as an 18th Sustainable Development Goal (SDG). The United Nations agreed on these SDGs in 2015, aiming at their achievement in 2030 (United Nations 2020):

The 2030 Agenda for Sustainable Development ... provides a shared blueprint for peace and prosperity for people and the planet, now and into the future. At its heart are the 17 Sustainable Development Goals (SDGs), which are an urgent call for action by all countries - developed and developing - in a global partnership. They recognize that ending poverty and other deprivations must go hand-in-hand with strategies that improve health and education, reduce inequality, and spur economic growth - all while tackling climate change and working to preserve our oceans and forests. (n.p.)

The SDGs hence range from 'No Poverty' and 'Zero Hunger' to 'Quality Education', 'Decent Work and Economic Growth' and 'Reduced Inequalities'. Environmental aspects include 'Clean Water and Sanitation' and 'Affordable and Clean Energy'; also, 'Climate Action', the need to take care of 'Life below Water' and 'Life on Land' are mentioned, but the planet's 'Space Environment' is left out. Why is this aspect of sustainability nevertheless important today? This is what the idea of planetary sustainability to be developed in this article will address.

Planetary sustainability, as understood here, is both a present need and a future vision. Although the term occasionally showed up in earlier academic discussions (Cairns 2001) and political frameworks (United Nations Educational, Scientific and Cultural Organisation [UNESCO] 2003), or could nowadays well be associated with the idea of planetary boundaries (Rockström et al. 2009; Steffen et al. 2015b; the connection is made in Galli \& Losch 2019), even before the 2030 agenda the National Aeronautics and Space Administration (NASA) envisioned a threefold scheme under this title:

1. a world in which all people have access to abundant water, food and energy, as well as protection from severe storms and climate change impacts

2. healthy and sustainable worldwide economic growth from renewable products and resources

3. a multiplanetary society, where the resources of the solar system are available to the people of Earth. (ed. NASA 2014) 
A pioneering research project at the University of Bern with a similar approach referred to NASA's ideas and in particular started with the analysis of the third bullet point of the vision (Losch 2016, 2018). Science fiction or reality? Current plans for space mining and a return to the moon - including a 'moon village' - blur the line. The research project focussed on the space dimension of planetary sustainability, although a more integrative approach including both our space environment and the planet Earth to some degree remains a desideratum until today. It is hence not unjustified to call for another name for that initial preliminary and limited approach (Beisbart 2019b; cf. Beisbart 2019a; Losch 2019b).

\section{Definition and scope of planetary sustainability}

Nevertheless, the term 'planetary sustainability' shall here be understood in the broad sense of the envisioned more integrative approach, including the planet Earth and its space environment basically as an understanding of sustainability awareness of the fact that the Earth is a planet. This may sound very basic but is important in at least two ways.

First of all, and related to the concept introduced here, this is relatively new, and we have to be aware of the limits that come with being a planet facing the Anthropocene (Crutzen 2002; Steffen et al. 2015a). According to Crutzen (2002):

For the past three centuries, the effects of humans on the global environment have escalated ... Unless there is a global catastrophe ... mankind will remain a major environmental force for many millennia. A daunting task lies ahead for scientists and engineers to guide society towards environmentally sustainable management during the era of the Anthropocene. (p. 23)

According to the analysis, humanity has already transgressed at least three planetary boundaries: the one for human interference with the global nitrogen cycle (through the growth of fertiliser use), the biodiversity boundary and the climate boundary (Rockström et al. 2009). To these must be added today the boundary for land-system change (which has been updated with a new control variable: the amount of forest cover remaining; Steffen et al. 2015b:2). On the other hand, through the implementation of the Montreal Protocol, ${ }^{1}$ 'humanity succeeded in reversing the trend with regard to the stratospheric ozone boundary' (Rockström et al. 2009). This shows the intent of the planetary boundaries, which are designed as warning signs, including a buffer before reaching a global threshold or tipping point (Steffen et al. 2015b:2). 'Humanity thus needs to become an active steward of all planetary boundaries ... in order to avoid risk of disastrous long-term social and environmental disruption' (Rockström et al. 2009). This 'suggests the need for novel and adaptive governance approaches at global, regional, and local scales' (Rockström et al. 2009). For this, the planetary boundary approach needs to be developed further (Steffen et al. 2015b:8). It has also become clear that two of the boundaries, protocol. climate change and biosphere integrity, are 'highly integrated, emergent system-level phenomena that are connected to all of the other P[lanetary] B[oundarie]s' and hence should be regarded as core planetary boundaries (Steffen et al. 2015b:6f).

The second aspect of awareness of the planetary shape of the Earth points to the fact that our planet has a space environment, which is already very intensively used these days. Although we probably know about this on a theoretical basis, our imagination often tricks us insofar as we tend to live emotionally still in an Aristotelian world. We gaze at the stars like at an infinite ceiling and are proud to know of the Earth as a globe, which was actually an ancient insight, included in the Aristotelian world view (Russell 1991). In our days, however, we need to be conscious of our space environment as well. Although 'planetary boundaries' and the Anthropocene are now well-received concepts, the awareness of what is happening in our space environment is largely limited to space agencies and space enthusiasts. We are set to pursue 'global goals', yet we need to think bigger and develop a 'planetary plan', transcending our imaginative limits.

The United Nations point out how the space environment can be used to help achieve the 17 SDGs. Satellites providing big land data are key in this context; they can warn against floods, fires or draught and help in rural and urban development (Di Pippo 2019):

With space science, technology and applications, we can for example track endangered species such as rhinoceroses to protect them from poachers, or provide imagery and data to farmers to help them monitor their crops, improve their yield, and avoid food shortages. We can use satellites to map the spread of diseases and public health emergencies, enable children to learn remotely, and observe damage after natural disasters. (p. 1)

The United Nations Office for Outer Space Affairs (UNOOSA) is also showing the impact of space for the fulfilment of the 17 SDGs with its Space4SDGS programme (UNOOSA 2019b).

\section{Space as a limited resource}

Satellites demonstrate clearly why we need to work on sustainability in space as well. What started with Sputnik in 1957 has led to more than 8600 objects being launched into outer space to date (UNOOSA 2019a). Almost 5000 satellites are still operating for different purposes. 'Just a few uncontrolled space crashes could generate enough debris to set off a runaway cascade of fragments, rendering near-Earth space unusable' (Witze 2018:25). Already impacts from

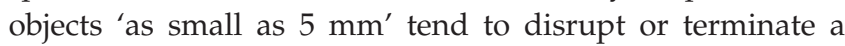
satellite's operations. Already, there are more incidents with space debris caused by the breakup of human-made devices than 'natural' events with micrometeorites (Bonnal \& McKnight 2017:5).

The normal way to get rid of space debris depends on the orbit into which the devices were launched. In the low Earth orbit (LEO), objects normally decay over time, when their 
orbits degrade and they enter the atmosphere. This does not happen to devices further away from the Earth; one 'solution' here is to move them after their service into a so-called graveyard orbit, where they would not endanger satellites currently in use. Pilot projects like CleanSpace One (EPFL Space Center 2019) - which turned into the start-up ClearSpace and received significant European Space Agency (ESA) funding in 2019 - try to take care of the problem and find technical solutions to clean up the space. The problem is that we can only observe debris above a certain size, depending on how far from the Earth the debris floats. Even in the LEO, we can only 'reliably and directly see and catalogue objects above about $10 \mathrm{~cm}^{\prime}$ (Bonnal \& McKnight 2017:5).

The Earth's space environment, especially the sought-after orbits, is a limited resource as well. Still, there are massive plans to increase the number of satellites. At the end of May 2019, SpaceX shot the first 60 Starlink satellites into space, which are considered to become part of an up to 12000 -satellite mega-constellation providing high-speed internet for every spot on the Earth (Mosher 2019). SpaceX is not the only company planning such constellations. Global capitalism and unilateral nationalism often encourage competition instead of cooperation in providing services and accessing data. Facing the plans for a multitude of such mega-constellations, astronomers worry about another potential future problem: as satellites are built to reflect sunlight to keep their instruments cool inside, the night sky could become significantly brighter. The International Astronomical Union (IAU 2019) and others have already voiced their concern:

\begin{abstract}
The organisation, in general, embraces the principle of a dark and radio-quiet sky as not only essential to advancing our understanding of the Universe of which we are a part, but also as a resource for all humanity and for the protection of nocturnal wildlife. We do not yet understand the impact of thousands of these visible satellites scattered across the night sky and despite their good intentions, these satellite constellations may threaten both. (n.p.)
\end{abstract}

Moreover, their radio emissions might be an issue, as the IAU goes on to say (IAU 2019).

\section{Space tourism}

Space tourism is already happening, and companies like Virgin Galactic, SpaceX and Boeing are working on its expansion. After Russia allowed space tourists into the International Space Station (ISS) in 2001-2009, NASA announced that it would welcome guests on the ISS as well. This is part of a strategy to privatise and commercialise the ISS by 2025 (NASA 2019). What is true for the USA is true in other parts of the world as well: space is changing from a domain of governments 'to a situation in which there is the increased number of diverse space actors around the world', as the ESA (2016) characterises it, 'including the emergence of private companies, participation with academia, industry and citizens, digitalization and global interaction.' The ESA calls the situation we face these days 'Space 4.0' (ESA 2016).
We are far away from mass tourism in space, yet to avoid future hazards we should dedicate some deliberations to the question of how space tourism can be organised in a truly sustainable manner.

\section{Space mining and settling}

As the economy plays a growing role in space, sustainability considerations also need to enter the discussion - all the more when it comes to the projected space mining. It is still under discussion as to whether the use of extra-terrestrial resources in outer space is actually legal and permitted by the Outer Space Treaty. Laws in the USA and in Luxembourg (which recently established a space agency and with its spaceresources. $l u$ initiative it is a major player when it comes to developing space-mining plans) provide national frameworks, which beg the question, are those frameworks internationally valid? Luxembourg has understood that it needs to cooperate with the international community to proceed, and it also vows to advance the issue in a sustainable manner: 'Luxembourg Aims to Contribute to the Peaceful Exploration and Sustainable Utilization of Space Resources for the Benefit of Humankind', as the headline claims (Luxembourg Space Agency 2018:n.p.; The Government of the Grand Duchy of Luxembourg 2019). The current time is of course characterised by preparatory moves; space mining itself is not yet in place (Luxembourg Space Agency 2018):

Although the time horizon for the first operational applications are expected to be in the next decade, preparatory steps are being taken today in developing the enabling technologies and obtaining prospecting information on future exploitable space resources. (p. 3)

In the short term, water (available on the moon, for instance) is the most sought-after space resource, both for rocket refuelling and for life support (Luxembourg Space Agency 2018:6). It is worth harvesting it in space, as it is quite expensive (and still risky) to launch anything into the Earth's orbit, so $1 \mathrm{~L}$ of usable water in space is currently worth more than $\$ 5000$ (pricing calculated according to SpaceX 2019). In the medium term, regolith mining could follow, for establishing infrastructure, for example on the moon. Next would be mining metals for space equipment, and finally, in the long run, platinum group metals could be brought back as resources to the Earth (Luxembourg Space Agency 2018:6).

This vision aims at the moon as the next place to go, but one should be aware that the Moon Agreement (valid for other celestial bodies as well) aims to share the profits envisioned on this celestial body (United Nations 1979):

The moon and its natural resources are the common heritage of mankind ... States Parties to this Agreement hereby undertake to establish an international régime ... to govern exploitation of the natural resources of the moon ... (Article 11)

Unfortunately, hardly any spacefaring nation signed this visionary moon agreement, so these words are somewhat void. 
With the recent concept of a moon village, brought forward by the ESA director general Jan Dietrich Wörner, there is now a vision for 'a permanent base station on the Moon ..., an open station, for different member states, for different states around the globe' (ESA:n.p.). This would probably include tourism, mining and satellite observation (ESA; Woerner 2016). It would be the first step towards space settling on a celestial body.

\section{Expansion into space?}

This review of actual and envisioned space activities has left out the military use of space, which is certainly a huge sector, but obviously not very public. On the moon and other celestial bodies, it is entirely forbidden (United Nations 1966:art. iv). We do not know, however, if this part of the treaty is being kept.

A more general question is about economic growth. Blue Origin (and Amazon) chief executive officer (CEO) Jeff Bezos envisions space as the place to continue economic growth, facing limited resources on the Earth (Blue Origin 2019), similar to the NASA idea presented initially. The vision of growth is built into the SDGs, as SDG 8 demands 'decent work and economic growth', coupling social well-being with the idea of growth, as mentioned. It needs to be discussed whether this is feasible, facing our planetary boundaries and how expansion into space can affect these aims.

What certainly is missing within the SDG discussion is an appreciation of our space environment as a somewhat threatened and, most of all, limited domain. This is why the idea has been proposed to establish an 18th SDG, our 'space environment', for facilitating discussions on the topic (see also Galli \& Losch 2019). I believe that it is important to refer to the space environment and not the space economy only (against the proposal of the National Space Society 2019), because else it would already present an imbalanced approach favouring the economic dimension of sustainability over its ecological and social dimensions.

What environmental concerns are valid for our space environment, besides that the one close to the Earth is a limited resource? A fundamental question regards the contamination of other celestial bodies with earthly microbiological life. The Outer Space Treaty is clear in that regards that (United Nations 1966):

States Parties to the Treaty shall pursue studies of outer space, including the Moon and other celestial bodies, and conduct exploration of them so as to avoid their harmful contamination and also adverse changes in the environment of the Earth resulting from the introduction of extra-terrestrial matter and, where necessary, shall adopt appropriate measures for this purpose. (Article ix)

Included here is not only forward, but also backward contamination, issues dealt with in the guidelines set up by the Committee on Space Research (COSPAR). The potential existence of ancient or even current extra-terrestrial life (ETL) on celestial bodies like Mars or Europa certainly adds a lot of complexity to the situation (Persson 2018). In general, the approach taken here is well expressed in the abstract of a recent article (Galli \& Losch 2019):

The current COSPAR Planetary Protection Policy addresses scientific space exploration only and is primarily concerned with the issue of contamination with micro-organisms. Other impacts of human space exploration that may be detrimental to space exploration itself are not covered. (p. 1)

\section{Ethical imperatives in dialog with Hans Jonas}

Let us reflect on the developments portrayed ethically and theologically, starting with some comments on Hans Jonas' early ethics of technology, which were pioneering in several regards. He introduced us to the ethical reflection on the fact that in our age, ethics must add a time horizon to the moral calculus (Jonas 1985:12), surpass the limits of the contemporary and involve deliberations of a responsible shaping of the future. Because of the vulnerability of nature (Jonas 1985):

[T] he nature of human action has de facto changed, and ... an object of an entirely new order - no less than the whole biosphere of the planet - has been added to what we must be responsible for because of our power over it. (p. 7)

This is the ethical dimension of what we call today the Anthropocene.

Jonas reaches, but also already surpasses, the scope of the modern concept of sustainability. According to the Brundtland definition, 'sustainability' is a 'development that meets the needs of the present without compromising the ability of future generations to meet their own needs', whilst these needs are 'in particular the essential needs of the world's poor' (World Commission on Environment and Development 1987:16.41). Jonas (1985) went beyond this idea, as he already questioned the anthropocentric fundament of our ethics, suggesting that:

$[T]$ he biosphere as a whole and in its parts ... has something of a moral claim on us not only for our ulterior sake but for its own and in its own right. (p. 8)

This has to be commemorated within the concept of a planetary sustainability by discussing alternative ethical stances like sentientism, biocentrism and holism.

Yet, Jonas was also wrong in some regards. When he summarises his new imperative with ' $[d]$ o not compromise the conditions for an indefinite continuation of humanity on Earth' (Jonas 1985:11), we should acknowledge that there is no indefinite continuation of humanity on Earth. A potential huge asteroid impact - as happened with the dinosaurs - can change the Earth forever. Within this framework, the recent idea of 'planetary defence' - the categorisation of asteroid 
threats and first missions to attempt to deflect them therefore makes sense. Yet in any case, the Earth's time is limited. In some 100 million years, the sun will have grown too hot and too big to allow for life on Earth, as is the sun's fate as a second-generation star. This is a lot of time but certainly not 'indefinitely' long, as Jonas phrased it. So Jim Pass is quite right in pointing out: 'without our expansion of our instruments and people into space, humanity could conceivably perish' (Pass, Dudley-Rowley \& Gangale 2006:5). 'To some extent, a truly sustainable concept of sustainability therefore has to be an inter-planetary one, which makes a continuous technological development a necessity' (Losch 2019a:262).

What follows is a counterintuitive answer to Jonas' concerns: to survive in the long run, we need our technology. It is not only a threat, but also our chance for sustainable (though not infinite) survival in our universe. Jonas' imperative of responsibility therefore must be paired with a technological imperative, because the Earth itself will perish.

\section{Transcending the heavens: Theological aspects}

Given the challenges of spacefaring, humankind has to settle into space rather sooner than later. Theology has to keep up with this challenge, because it currently is still very geocentrically orientated. The story it tells with its formative events all take place on the Earth, although their cosmic dimension is assumed. We have to reconstruct our theology, asking our traditions for answers for a truly cosmic approach. Losch and Krebs (2015), for instance, point out that the biblical opening statement that God created the heavens and the Earth is certainly not meant to be confined to our planet Earth; any habitable land can be considered earth (arez), as the biblical writers had no idea of the concept of a planet and hence also no intent to limit the idea to our planet.

Likewise, the heavens are often regarded as God's place or at least as a celestial space, following the Aristotelian tradition. The legend around Yuri Gagarin's first space flight that there was 'no God to be found' in space reflects these convictions. Hans Blumenberg (1965:11) showed the enlightening impetus of humankind's study of the heavens, highlighting the role of astronomy as a sort of exemplary trial of the human mind to demonstrate its own capacity and also the universal objectification of nature. No region of our world is taboo anymore, no access prohibited for human curiosity. Historian Lynn White (1967:1205) questioned the modern JewishChristian tradition of taboolessness as an exemplification of a careless approach to nature: 'By destroying pagan animism, Christianity made it possible to exploit nature in a mood of indifference to the feelings of natural objects'.

Therefore, it is humankind's most important task, as images of God, to preserve the heavens and the Earth, as both are creatures (Losch 2020a:79-86). Although the ecological perspective is relatively strong within the churches of our time, and an ecotheology has already been established, only recently has an astrotheology been reproposed (Derham 1715; Peters 2014; Peters, Hewlett \& Moritz 2018), but it mostly lacks an ecological perspective regarding our space environment (but cf. eds. Lehmann Imfeld \& Losch 2018).

\section{The wider context: Astroethics}

In 2014 Ted Peters called for astroethics, comprising both (1) 'microbiological life in our solar ghetto' and (2) 'intelligent life in the larger Milky Way metropolis' (Peters 2014:447; cf. Peters 2015). Within this framework, the focus of planetary sustainability certainly is within the context of the first point, and more 'down to Earth' than discussions about colonising or even potentially terraforming Mars. Although microbial ETL in our solar systems seems possible to me given the abundance of organic molecules in space - we must be conscious of the fact that no ETL has yet been found. In this regard, planetary sustainability as a sort of 'space environment ethics' is a much more realistic approach than speculations about ETL, although of course even the potential existence of ETL generates complex ethical problems and discussions (Persson 2018). Peters must be lauded for his efforts to explore the theological and ethical dimensions of our universe, yet the current focus on our space environment as a pressing field of sustainability concerns should not be lost.

\section{Summary}

Ethically evaluated, the idea of sustainability - best expressed in the Brundtland definition mentioned - is about intergenerational justice (Vogt 2009:133). Planetary sustainability adds a planetary scope and time-frame to this discussion, involving both the recognition of the limitations of our planetary boundaries and the potential gains in exploring our space environment. Whether the growth paradigm can be continued (as SDG 8 suggests) by extending growth into space, however, needs to be discussed. Ethical deliberations regarding the space domain need to include the important role of satellites for the Earth's economy and technological society, the growing threat of space debris, the role of space tourism, our ambitious plans to return to the moon and settle in space, and sustainable space-mining considerations. Theologically, Hans Jonas has foreseen important problems of our technological age, and we need to discuss anthropocentrism, often taken for granted within theology. Against Jonas, the role of technology, however, needs to be reassessed more appreciatively, as only technology can prolong humankind's survival in the universe in the long run. Although this article does not propose a distinct scenario for humankind's future, its observation and theological assessment is that the heavens are not taboo anymore; they have to be discovered and explored as a creaturely domain.

There are many more questions to be explored, a task that could be settled within the emerging field of astroethics, if it is not restricted to issues surrounding ETL only. The existence of 
ETL would add many ethical and sustainability questions for sure; its potential microbial existence in our solar system already does. Yet also, without ETL, there are many pressing ethical concerns involving our space environment, which could be overlooked if one were too focussed on the impact of potential ETL only. Our 'space environment' is worth being integrated into the United Nations' SDGs as an 18th goal of its own, developing the Global Goals into a truly Planetary Plan.

\section{Acknowledgements}

The argument in this article is based on an adapted and extended version of Losch 2020b. This is an Open Access article, distributed under the terms of the Creative Commons Attribution- NonCommercial-ShareAlike.

\section{Competing interests}

The author declares that he has no financial or personal relationships that may have inappropriately influenced him in writing this research article.

\section{Author's contributions}

A.L. is the sole author of this research article.

\section{Ethical considerations}

This article followed all ethical standards for research without direct contact with human or animal subjects.

\section{Funding information}

This research builds on the project 'Ethics of Planetary Sustainability', funded by the Cogito Foundation and crowd funding.

\section{Data availability statement}

Data sharing is not applicable to this article as no new data were created or analysed in this study.

\section{Disclaimer}

The views and opinions expressed in this article are those of the author and do not necessarily reflect the official policy or position of any affiliated agency of the author.

\section{References}

Beisbart, C., 2019a, 'Is trans-planetary sustainability a good idea?: An answer from the perspective from conceptual engineering', International Journal of Astrobiology 18(5), 468-476. https://doi.org/10.1017/S1473550418000472

Beisbart, C., 2019b, '(Trans-)planetary sustainability once more: A reply to Losch', International Journal of Astrobiology 18(6), 1-2.

Blue Origin, 2019, Our mission, viewed 28 December 2019, from https://www. blueorigin.com/our-mission.

Blumenberg, H., 1965, Die kopernikanische Wende, 1st edn., Suhrkamp Verlag, Frankfurt am Main.

Bonnal, C. \& McKnight, D.S., 2017, IAA situation report on space debris - 2016, International Academy of Astronautics, Paris.

Cairns, J., 2001, 'The age of transition to sustainability: The end of the exponential growth period', Politics and the Life Sciences 20(2), 131-138. https://doi. org/10.1017/S0730938400005426
Crutzen, P.J., 2002, 'Geology of mankind', Nature 415, 23. https://doi.org/10.1038/ $415023 a$

Derham, W., 1715, Astro-theology: Or a demonstration of the being and attributes of God, from a survey of the heavens. Illustrated with copper plates, W. Innys, London.

Di Pippo, S., 2019, 'The contribution of space for a more sustainable Earth: Leveraging space to achieve the sustainable development goals', Global Sustainability 2(e3), 1-3. https://doi.org/10.1017/sus.2018.17

EPFL Space Center, 2019, The CleanSpace one: Our mission: Sustainability in space and beyond, viewed 17 August 2020, from https://www.epfl.ch/research/domains/ epfl-space-center/spaceresearch/cleanspaceone_1/.

European Space Agency, 2016, What is Space 4.0?, viewed 28 July 2017, from https:// www.esa.int/About_Us/Ministerial_Council_2016/What_is_space_4.0.

European Space Agency, 2019, ESA Euronews: Moon Village, viewed 28 December 2019, from https://www.esa.int/Education/Teach_with_the_Moon/ESA_Euronews Moon_Village.

Galli, A. \& Losch, A., 2019, 'Beyond planetary protection: What is planetary sustainability and what are its implications for space research?', Life Sciences in Space Research 23, 3-9. https://doi.org/10.1016/j.Issr.2019.02.005

International Astronomical Union, 2019, IAU statement on satellite constellations, viewed 14 June 2019, from https://www.iau.org/news/announcements/detail/ ann19035/.

Jonas, H., 1985, The imperative of responsibility: In search of an ethics for the technological age, The University of Chicago Press, Chicago, IL.

Lehmann Imfeld, Z. \& Losch, A. (eds.), 2018, Our common Cosmos: Exploring the future of theology, human culture and space sciences, T \& T Clark, London.

Losch, A. \& Krebs, A., 2015, 'Implications for the discovery of extraterrestrial life: A theological approach', Theology and Science 13(2), 230-244. https://doi.org/ 10.1080/14746700.2015.1023522

Losch, A., 2016, 'Planetare Nachhaltigkeit. Annäherung an ein Projekt', in C. Wustmans (ed.), Öffentlicher Raum: Theologische, religionswissenschaftliche und ethischnormative Dimensionen, Sozialethische Materialien 4, pp. 181-188, Hartmut normative Dimensi
Spenner, Kamen.

Losch, A., 2019a, 'The need of an ethics of planetary sustainability', Internationa Journal of Astrobiology, 18(3), 259-266.

Losch, A., 2019b, 'Planetary sustainability: Transitions of an idea', Internationa Journal of Astrobiology 18(6), 592-594.

Losch, A., 2020a, 'Preserving the heavens and the Earth: Planetary sustainability from a biblical and educational perspective', in M. Fuller, D. Evers, A. Runehov, K.-W. Sæther \& B. Michollet (eds.), Nature and beyond: Transcendence and immanence in science and religion, Science and Religion: Publications of the European Society for the Study of Science and Theology, vol. 5, pp. 79-86, Springer, Cham.

Losch, A., 2020b, 'Editorial: Planetary sustainability collection', Global Sustainability 3(e13), 1-3. https://doi.org/10.1017/sus.2020.7

Luxembourg Space Agency, 2018, Opportunities for space resources utilization: Future markets \& value chains, viewed 10 June 2019, from https://space-agency.public. lu/dam-assets/publications/2018/Study-Summary-of-the-Space-ResourcesValue-Chain-Study.pdf.

Mosher, D., 2019, Elon Musk just revealed new details about Starlink, a plan to surround Earth with 12,000 high-speed internet satellites: Here's how it might work, viewed 17 August 2020, from https://www.businessinsider.com.au/spacexstarlink-satellite-internet-how-it-works-2019-5.

National Aeronautics and Space Administration (NASA) (ed.), 2014, Our vision for planetary sustainability, viewed 01 November 2016, from https://www.nasa.gov/ content/planetary-sustainability-our-vision/\#.WBgtmiTBZsl.

National Aeronautics and Space Administration (NASA), 2019, NASA opens International Space Station to new commercial opportunities, private astronauts: Release 19-044, viewed 17 August 2020, from https://www.nasa.gov/pressrelease/nasa-opens-international-space-station-to-new-commercial-opportunitiesprivate.

National Space Society, 2019, The 18th sustainable development goal: Recognizing the imperative role of space in our future, viewed 30 December 2019, from https:// www.unoosa.org/documents/pdf/copuos/lsc/2018/tech-04.pdf.

Pass, J., Dudley-Rowley, M. \& Gangale, T., 2006, 'The cultural imperative to colonize space: An astrosociological perspective', Aerospace Research Central, San Jose, CA

Persson, E., 2018, 'A philosophical outlook on potential conflicts between planetary protection, astrobiology and commercial use of space', in Z. Lehmann Imfeld \& A. Losch (eds.), Our common cosmos: Exploring the future of theology, human culture and space sciences, pp. 141-160, T \& T Clark, London.

Peters, T., 2014, 'Astrotheology: A constructive proposal', Zygon ${ }^{\circledR} 49(2), 443-457$.

Peters, T., 2015, 'Ten ethical issues in exploring our Solar Ghetto', Journal of Astrobiology \& Outreach 4(1), 1-8. https://doi.org/10.4172/2332-2519. 1000149

Peters, T., Hewlett, M. \& Moritz, J.M., 2018, Astrotheology: Science and theology meet extraterrestrial life, Wipf and Stock Publishers, Eugene, OR.

Rockström, J., Steffen, W., Noone, K., Persson, Å., Chapin, F.S., III, Lambin, E. et al., 2009, 'Planetary boundaries: Exploring the safe operating space for humanity', Ecology and Society 14(2), 32. https://doi.org/10.5751/ES-03180-140232

Russell, J.B., 1991, Inventing the flat Earth: Columbus and modern historians, Praeger, New York, NY.

SpaceX, 2019, Capabilities and services, viewed 28 December 2019, from https:// www.spacex.com/. 
Steffen, W., Broadgate, W., Deutsch, L., Gaffney, O. \& Ludwig, C., 2015a, 'The trajectory of the Anthropocene: The great acceleration', The Anthropocene Review 2(1) 81-98.

Steffen, W., Richardson, K., Rockström, J., Cornell, S.E., Fetzer, I., Bennett, E.M. et al., 2015b, 'Sustainability. Planetary boundaries: Guiding human development on a changing planet', Science (New York, N.Y.) 347(6223), 1-17. https://doi. org/10.1126/science.1259855

The Government of the Grand Duchy of Luxembourg, 2019, Luxembourg aims to contribute to the peaceful exploration and sustainable utilization of space resources for the benefit of humankind, viewed 10 June 2019, from https:// spaceresources. public.lu/en.html.

United Nations Educational, Scientific and Cultural Organisation (UNESCO), 2003, Planetary sustainability in the age of the information and knowledge society for a sustainable world and future, viewed 11 December 2017, from www.undocuments.net/psaiks.pdf.

United Nations Office for Outer Space Affairs (UNOOSA), 2019a, Online index of objects launched into outer space, viewed 10 June 2019, from https://www. unoosa.org/oosa/osoindex/search-ng.jspx?lf id =

United Nations Office for Outer Space Affairs (UNOOSA), 2019b, Space supporting the sustainable development goals: How space can be used in support of the 2030 agenda for sustainable development, viewed 30 January 2020, from https://www. unoosa.org/oosa/en/ourwork/space4sdgs/index.html.
United Nations, 1966, Treaty on principles governing the activities of states in the exploration and use of outer space, including the moon and other celestia bodies, viewed 28 December 2019, from https://www.unoosa.org/pdf/gares/ ARES_21_2222E.pdf.

United Nations, 1979, Agreement governing the activities of states on the moon and other celestial bodies, viewed 28 December 2019, from https://www.unoosa.org/ pdf/gares/ARES_34_68E.pdf.

United Nations, 2020, Sustainable development goals, viewed 02 June 2020, from https://sustainabledevelopment.un.org/?menu=1300.

Vogt, M., 2009, Prinzip Nachhaltigkeit: Ein Entwurf aus theologisch-ethischer Perspektive, Oekom-Verl, München.

White, L., 1967, 'The historical roots of our ecologic crisis', Science (New York, N.Y.) 155(3767), 1203-1207.

Witze, A., 2018, 'The quest to conquer Earth's space junk problem', Nature 561(7721), 24-26.

Woerner, J., 2016, Moon village: A vision for global cooperation and Space 4.0, viewed 15 October 2017, from https://www.esa.int/About_Us/Ministerial_Council_2016/ Moon_Village.

World Commission on Environment and Development, 1987, Our common future, 1st edn., Oxford University Press, Oxford. 